\title{
Environmental Risk Discrimination and Assessment for Municipal Solid Waste Secure Landfill Site
}

Cao Yonghong

Urban and Environmental Sciences School, Northeast Normal University, Changchun 130024, China

\begin{abstract}
With development of urbanization, the amount of municipal solid waste is increasing. Landfill is the main method for disposing the urban garbage at present in China. But the secure landfill site is not safe completely because it has a lot of risks threatening surrounding environment. After types of environmental risk in municipal solid waste secure landfill site were analyzed, I summarized that the risks in waste secure landfill site include water environment risks, air environment risks and waste pile sliding risks which are results caused by anthropic, equipment and natural factors. The methods of calculating risk probability, affecting scope and intensity were presented. The ways and means of risk prevention and management were put forward.
\end{abstract}

Keywords: Municipal solid waste; secure landfill site; environmental risk.

\section{城市生活垃圾安全填埋场环境风险因素识别与评价}

曹勇宏

东北师范大学城市与环境科学学院, 长春 130024 , 中国

摘要: 随着城市化进程的加快, 各个城市的生活垃圾产生量也日益增多。卫生填埋仍然是我国处理生活 垃圾的主要途径。但安全填埋场并不安全, 其存在着很多风险因素威胁着周围区域环境的安全。分析了城市生 活垃圾安全填埋场存在的各种风险类型, 认为人为风险、设备风险以及自然风险是诱因, 水环境风险、大气环 境风险、垃圾堆体滑动风险是结果, 提出了估算垃圾场风险发生概率、风险影响范围及影响强度的方法, 最后 阐明了填埋场风险防范措施。

关键词: 生活垃圾, 安全填埋场, 环境风险

环境风险是指在一定区域或环境单元内，通过 介质传播的, 由人为活动或自然等原因引起的 “意 外”事故对人类、社会与生态等造成的不良影响。 而环境风险评价是对环境风险事件发生的概率、影 响的范围、后果的严重程度、可能带来的损失等进 行评估并提出相应对策的过程 $[1,2,7]$ 。

随着我国城市化进程的加快, 城市垃圾的产生 量也在迅速增长, 而且伴随着居民生活水平的提 高、城市工业结构和能源结构的调整, 城市垃圾的 组成成分也越来越复杂, 增加了城市垃圾的处理难 度。目前, 垃圾的处理方式主要有堆肥、焚烧、回 收利用及填埋。由于填埋法成本低、技术简单、处 理迅速, 仍然是我国应用最为广泛的垃圾处置方 式。

虽然垃圾填埋场使生活垃圾得到了有效的处 置, 但并没有消除其污染性与有害性, 并且这种集
中堆放的方式还会产生一些新的污染风险。比如垃 圾渗滤液的外泄事故 [3]、填埋气火灾爆炸事故 [4], 都严重威胁着填埋场以及填埋场周围的环境安全。 这意味着垃圾安全填埋场并不是绝对地安全, 其中 存在着许多风险及不安全因素。如能有效地识别风 险、规避风险, 并在此基础上进行有效的风险管理 对保障一个区域的环境安全具有十分重要的意义。

\section{1. 城市垃圾安全填埋场正常运转时的污染与风 险防治措施}

\section{1 填埋场主要污染与环境风险}

垃圾填埋场的主要污染因素为垃圾渗滤液、扬 尘、恶臭、随风刮动的塑料、纸张、垃圾堆体滑动 等。主要的风险因素为垃圾渗滤液的外泄、以甲烷 为主要成分的填埋气体的爆炸。 


\subsection{1 垃圾渗滤液}

垃圾渗滤液中含有大量的高浓度有毒物质, 如 果不经处理排入到环境中, 则会使生态系统受到严 重污染和损害, 并通过食物链对人体健康产生威胁 [5]。垃圾渗滤液来源主要有三种, 一是垃圾内的含 水成分在垃圾堆体的强大压力下，水分被挤压出 来; 第二部分为垃圾内的有机成分发生生化反应产 生的水分; 第三部分为降落到垃圾堆体上的雨水以 渗滤液的形式排出。

\subsection{2 填埋气体}

填埋气体主要是由于垃圾内的有机成分在微生 物生化降解作用下, 产生甲烷、二氧化碳、氨气、 水以及硫化氢等混合性气体(填埋气)。

垃圾填埋场对上述两种主要污染与风险因素通 常采取以下工程与管理措施进行防治。

\section{2 工程防治措施}

\subsection{1 垃圾渗滤液污染防治措施}

\section{(1) 基底与边坡防渗措施}

垃圾场底部以及边坡的水平防渗层主要是利用 聚乙烯材料、土工布或者是其它防渗效果好的材料 进行防渗, 同时辅以粘土压实等方法, 可以增加防 渗性并可有效防止防渗材料被石头等硬物划破。垃 圾堆放场地在没有边坡拦挡的开口处要建设具有防 渗性能的垃圾坝, 并在坝下采用垂直帷幕灌浆的方 法进行垂直防渗。从而形成垂直与水平相结合的防 渗系统。

\section{（2）导流措施}

在垃圾堆埋体内设置坚向集水石笼(兼导气管), 在底部的防渗层上设置以碎石或卵石为材料的盲 沟, 把垃圾渗滤液导入收集池内。

\section{（3）收集池}

渗滤液收集池除了要具有良好的防渗性能外, 其 最大设计容量要充分考虑到垃圾渗滤液的正常产量 以及在大雨、垃圾液处理设施不能正常运转等风险 因素。
（4）雨水截流措施

为了减少雨水汇入垃圾堆体而增加渗滤液的产生 量, 需要在填埋区四周的边坡上挖设雨水截流沟, 把降落在填埋区以外的雨水导出填埋区。

\section{（5）处理设施}

经过集中收集的渗滤液处理方法主要有三种: (1) 将渗滤液输送到城市污水处理厂与城市生活污水 合并处理; (2)采用渗滤液回灌技术处理, 其主要原 理是把渗滤液回灌到垃圾堆体上, 增加蒸发量, 从 而使渗滤液减量; (3)由填埋厂自建渗滤液处理站处 理, 采用的工艺包括生物法、物化法与土地法等 [5]。

\section{2 .2 填埋气的疏导措施}

主要是在垃圾堆体内合理布设石笼和排气井, 使填埋气体能得到有效排散。

\section{3 风险管理措施}

填埋区要划分为若干作业区, 垃圾被倾倒入某作 业区后, 要立即进行平整压实, 以降低垃圾空隙 率, 减少沉降。每达到隔 $2-5 \mathrm{~m}$ 厚度时要进行覆土 并压实, 可有效减少进入垃圾层的降雨量, 避免垃 圾层因雨水过多而失稳, 并可减少渗滤液的产生 量。

\section{2. 城市垃圾安全填埋场的风险因素识别}

垃圾填埋场的风险类型按照不同的分类标准可 以有多种。按风险定义的内涵可以分为广义风险与 狭义风险。按风险诱发因素可以分为人为风险、设 备风险以及自然风险。按风险类别可以分为水环境 风险、大气环境风险、垃圾堆体滑动风险等。而这 些风险又存在着必然的联系，人为风险、设备风险 以及自然风险是诱因, 水环境风险、大气环境风 险、垃圾堆体滑动风险是结果。人为风险与设备风 险属于事故风险范畴, 而自然风险属于潜在风险范 畴。各种风险之间的联系见图1。

\section{1 广义风险与狭义风险}

广义风险是指凡是对生态系统或者是人体健康 造成威胁的所有污染事件, 无论大小都统称为风 


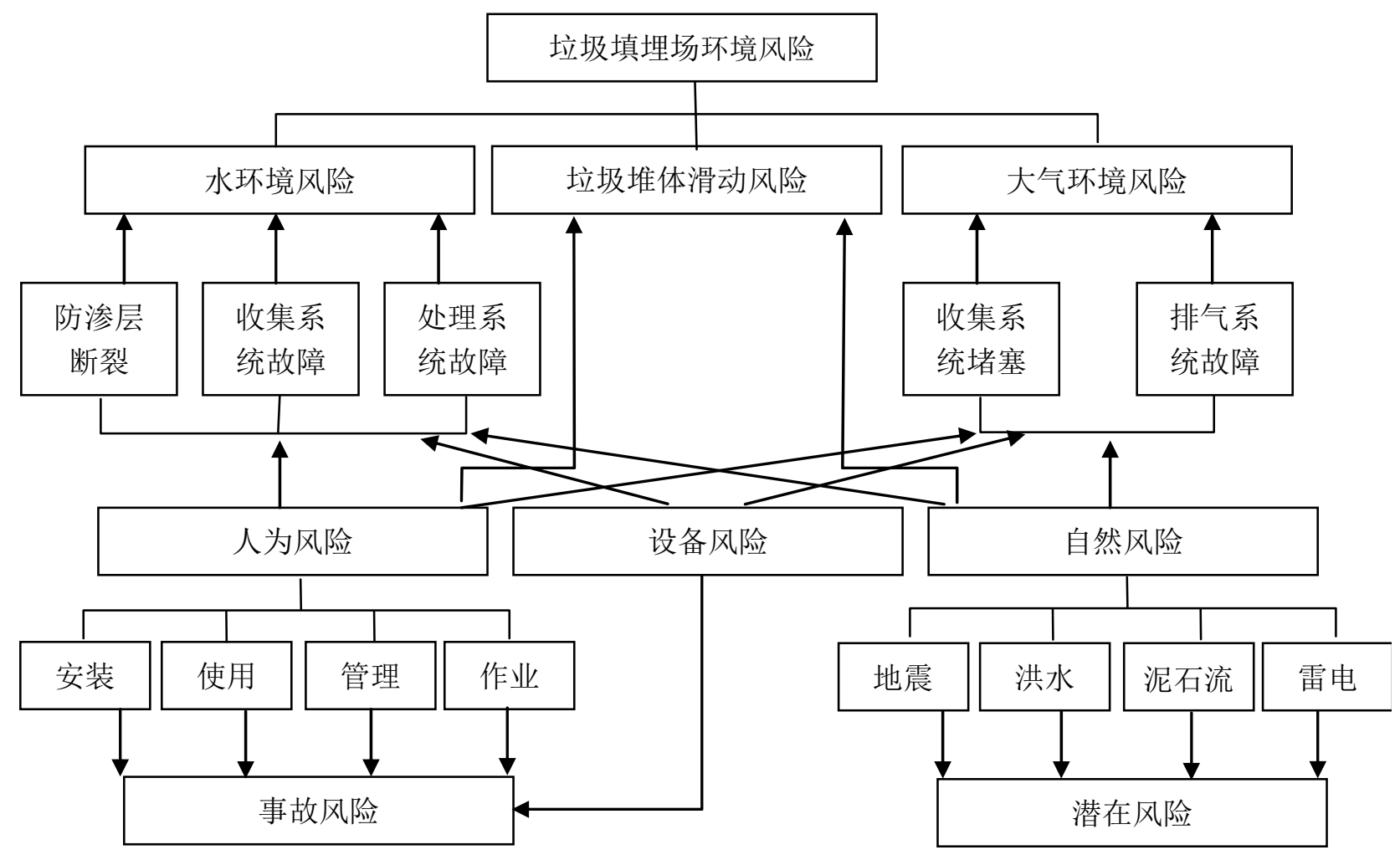

图 1 生活垃圾填埋场风险类型图

险。按风险发生的机制又可以为分常规风险、事故 风险与潜在风险 $[6]$ 。狭义风险是指具有一定发生概 率的, 一旦发生会造成生态系统、人员伤害的, 或 者造成一定经济损失的环境事件, 特指广义风险中 的事故风险以及潜在风险。

\section{1 .1 常规风险}

常规风险是指垃圾填埋场各种设施在正常运行 时, 向环境排放的有害物质。例如运输与填埋机械 作业时发出的噪音, 运输、倾倒、碾压、平整垃圾 过程中随风飘散的纸张、塑料、扬尘, 垃圾堆体、 垃圾渗出液产生的恶臭以及甲烷气体, 还有渗滤液 收集系统收集的垃圾液等。因为这些因素对环境以 及人群尚不能构成严重威胁, 所以人们常把他们称 为污染因素而不是风险因素。

\section{1 .2 事故风险}

由于设备的老化、丢失以及人为操作失误，使 垃圾填埋场设施发生故障, 致使经济受到损失、环
境遭到损害、以及人员造成伤亡的事件。例如垃圾 渗滤液防渗系统、收集系统、处理系统发生损坏或 故障，造成垃圾渗滤液的外泄；可燃气体收集与导 气系统发生故障, 造成可燃气体郁集以至于爆炸 等; 能源供给系统发生故障造成填埋场无法正常作 业而被迫关闭等。

\subsection{3 潜在风险}

是指垃圾填埋场中那些环境危害而暂时还没有 条件发生的风险。它们发生的机率很小, 但是一旦 发生却具有很大的破坏性以及危害性。例如地震造 成填埋区防渗层破裂使渗滤液外泄事故。

\section{2 人为风险、设备风险、自然风险}

\subsection{1 人为风险}

是指填埋场的设备在安装、使用、管理过程 中，或者在垃圾场运营过程中，工作人员违规作业 造成填埋场设施损坏、不能正常运转, 从而造成垃 
圾填埋场的污染外泄与爆炸等世故。例如进行垃圾 填埋区底部防渗时, 防渗膜的铺设需要有严格的操 作规程, 如果不按规程进行操作, 极易出现防渗膜 接合不严, 或者石头等硬物的垫、硌造成防渗膜破 损等, 都会引起垃圾渗滤液外漏, 进而发生污染地 下水事故。如果在垃圾堆埋过程中, 垃圾堆体不能 及时覆土压实, 在突遇大雨的情况下, 雨水就会进 入垃圾堆体转变为垃圾渗滤液, 使垃圾渗滤液的产 生量迅速增加, 一旦超出收集池的收集容量或者超 过污水处理设施的处理能力, 就会造成渗滤液外 溢，造成污染地表水的环境风险。

\section{2 .2 设备风险}

是指用于垃圾填埋场基础设施建设的材料、设 备等质量存在问题，或者是材料、设备年久失效， 从而使垃圾场在运营过程中, 发生污染或爆炸事 故。

\section{2 .3 自然风险}

是指自然界发生的偶然事件，使填埋场发生了 爆炸与污染事故。例如由洪水、地震、滑坡、泥石 流、自然雷击等自然灾害造成垃圾场设备毁坏或者 是无法正常运转而造成的垃圾渗滤液泄露、可燃气 体爆炸等事故。

2.3 水环境风险、大气环境风险、垃圾堆体滑动风险

\section{3 .1 水环境风险}

是指由于人为或者是自然原因引起的垃圾渗滤 液的外泄事件, 从而对周围环境构成了一定的威 胁。水环境风险的可能性包括以下两方面。

\section{（1）防渗层破裂}

地震、防渗层敷设时由于施工不规范导致基础 不均匀沉降、聚乙烯膜接合处衔接不严密、机械碾 压时造成聚乙烯膜破裂、防渗材料质量低劣都可以 造成防渗层破裂，其威胁对象主要是地下水。

\section{（2）集水系统及水污染处理系统失效}

当集水系统发生损坏，或者污水处理站因故无 法正常运行, 以及突遇大雨、洪水, 超出集水池的 负荷或者超出污水处理系统的处理能力使污水未经
处理而排放。其威胁的对象主要是地表水环境以及 附近的生态系统。

\section{3 .2 大气环境风险}

当垃圾堆体内收集系统堵塞或者是排气系统设 计有缺陷时, 造成以甲烷为主要成分的填埋气在垃 圾场内郁集，达到爆炸极限时，一旦遇上高温、明 火、雷击、电火花等, 就会发生火灾或者是爆炸。

\subsection{3 垃圾堆体沉降或滑动引起的环境风险}

当垃圾堆总体高度过大, 垃圾中的有机组分经 过降解, 会导致垃圾堆的自压缩与沉降, 由此带来 堆场的不稳定风险。一旦遇较大降雨, 垃圾场产生 滑坡的几率就会增大, 周边的自然以及人工生态系 统都将受到危害[2]。

\section{3. 城市垃圾卫生填埋场风险大小及影响范围评 价方法}

环境风险评价应该主要包括对风险大小的预 测、事故后污染影响范围的预测以及污染物质扩散 浓度的预测 [8]。生活垃圾填埋场风险大小，以及事 故发生后能否对一定时间内其影响范围大小进行合 理估测, 对环境风险应急预案的制定以及风险发生 后处理措施的有效执行可以提供重要的依据。

\section{1 垃圾填埋场污染风险的度量}

垃圾填埋场的风险是多种因素综合作用的结 果，应该根据其所在区域的自然条件、社会经济条 件及垃圾场的工艺条件进行综合评价。其综合评价 指数计算方法如下:

$$
C I=R \times D \times S O \times E
$$

其中:

$\mathrm{CI}$ ：垃圾填埋场风险评价综合指数;

$\mathrm{R}$ : 填埋场运营过程中的工艺风险指数;

D: 区域自然灾害风险指数, 是指区域地震、洪水 等自然灾害对填埋场风险发生的影响，根据各 自然灾害发生的概率与可能性确定;

SO: 区域社会指数, 指社会消防能力、交通情况、 管理部门的组织应急能力对垃圾填埋场环境风 险的影响。

$\mathrm{E}$ : 环境指数, 表示事故发生后, 事故对环境及人群 影响的程度。 
工艺风险指数 $\mathrm{R}$ 是由多种因素综合决定的, 其 由下式来进行计算,

$$
R=\sqrt[5]{C \times T \times S \times M \times B}
$$

其中:

C: 危险指数, 表示填埋场固有的、潜在的污染事故 的危险程度。它决定于填埋场拥有的污染物的数 量、毒性、燃烧爆炸性等。

$$
C=\sum_{j=1}^{m} \sum_{i=1}^{n} A_{i j} \times M_{i j}
$$

( $A$ 为事故隐患指数, $M$ 为权重, $i$ 为评价项目个 数, $j$ 为第 $j$ 种污染因子) ;

$\mathrm{T}$ : 工艺指数, 是指填埋工艺过程对环境风险的影 响。 $T=\sum_{i=1}^{n} T_{i}$ （i 为有环境事故风险的工艺环 节)；

$\mathrm{S}$ : 安全指数, 是指垃圾场安全等级的指标, 它反映 填埋场生产装置、设备的可靠程度、安全环保管 理系统的水平。 $S=\sum_{i=1}^{n} S_{i}$ (i 为影响垃圾场安 全的设施因子）；

$\mathrm{M}$ : 安全管理指数, 主要反映管理者和操作者素质 的高低, 对职工的安全教育状况和日常安全管 理状况;

$\mathrm{B}$ : 殉爆指数：是指爆炸时引起一定距离外另一爆炸 的发生，在填埋场指一填埋单元发生事故后能 否引起另一单元事故的发生;

区域自然灾害风险指数 D由各自然灾害发生概 率与可能性共同决定, 其大小由下式计算,

$$
D=(F+E Q+L+L S) / 4
$$

其中:

$\mathrm{F}$ : 区域洪水风险指数, 是指区域洪水对填埋场风险 发生的影响，根据洪水发生的概率与可能性确 定;

EQ: 区域地震风险指数, 根据地震裂度级别与地震 发生的可能性确定;

$\mathrm{L}$ : 滑坡风险指数, 填埋区周围山体滑坡对填埋场风 险发生的影响，根据滑坡发生的概率确定;

LS：雷击风险指数, 指雷击事件对填埋场发生爆炸 风险的影响，根据雷击事件发生的概率确定。 SO、E 以及 $R 、 D$ 指数计算过程中的指标、标 准应参考各种相关资料并向专家咨询而得到。

3.2 事故发生后污染物影响范围与浓度预测
垃圾场发生的污染风险中, 大气事故风险主要 表现为爆炸，为瞬时性事件; 而水环境污染事故风 险影响范围大、影响时间长，所以对风险事故影响 范围与浓度的预测, 应主要集中在对水污染事故的 预测与评估上, 包括对地下水和地表水的污染预测 与评估。

\subsection{1对地下水的影响范围与污染物浓度预测}

当垃圾场底部防渗层破损失效时, 垃圾渗滤液 就会经过包气带进入含水层。污染物在岩土层中, 会产生对流和弥散、机械过滤、吸附和解析、化学 反应、沉淀和溶解、降解和转化等一系列复杂的物 理、化学、水文地球化学和生物作用。因此, 对地 下水影响范围与浓度的预测, 除了要考虑渗滤液的 化学成分、浓度、以及入渗条件之外, 还要考虑包 气带的地质结构、岩土成分、厚度、饱和和非饱和 渗透性能和对污染物的吸附滞留能力等因素的影 响, 因此需要根据渗滤液的特点以及当地的自然条 件, 而建立复杂的预测模式。为了反应一般情况下 的普遍规律, 我们需要设立一些假设条件, 从而建 立起理想状态下的一般预测模型。

（1）下游某点处的污染物浓度预测

假设地下含水层为各向同性的均匀孔隙介质, 污染物在固相上吸附遵从 Henry 吸附平衡关系, 污 染物的降解或衰变常数为 0 , 即污染物是守恒的。 污染物在下游某一点处浓度 $\mathrm{C}$ 可按下式求得:

$$
C=\int_{0}^{t} f(\tau) C_{1}(t-\tau) d \tau
$$

式中:

$\mathrm{f}(\tau)$ : $\tau$ 时刻源的释放率;

$\mathrm{C}_{1}(\mathrm{t}-\tau)$ : 在（t- $\tau$ ) 时刻, 下游某点处的浓度;

（2）污染物的渗透速度

对于非饱和及饱和状态流场, 可以采用统一的达 西定律。

式中,

$$
q_{i}=-k_{i j} \frac{\partial h}{\partial X_{i}}
$$

$q_{i}$ : 渗透速度;

$\mathrm{k}_{\mathrm{ij}}$ : 渗透系数张量;

$\mathrm{h}$ : 水头。

3.2.2 地表水的影响范围与浓度预测 
当垃圾渗滤液进入到地表水体以后, 污染物的 浓度会随着时间和空间的推移而逐渐降低, 即发生 了水体的自净作用, 自净作用的机制可以分为物理 自净、化学自净和生物自净三类, 它们往往是同时 发生而又相互影响。上述各种过程要受到受纳水体 的大小、水量、水速、水质等一系列水文特征的影 响。因此, 进入到河流、湖泊、海洋等不同的水体 中, 要采用不同的预测模式, 下面以污染物排入均 匀恒定的河流为例, 说明对地表水影响范围与浓度 预测的方法。

\section{（1）持久性污染物的浓度预测}

当持久性污染物随垃圾渗滤液排入均匀恒定的 河流后, 经过混合过程段到达充分混合段时, 污染 物的浓度可按河流完全混合模式求得：

其中:

$$
\mathrm{C}=\left(\mathrm{C}_{\mathrm{p}} \mathrm{Q}_{\mathrm{p}}+\mathrm{C}_{\mathrm{h}} \mathrm{Q}_{\mathrm{h}}\right) /\left(\mathrm{Q}_{\mathrm{p}}+\mathrm{Q}_{\mathrm{h}}\right)
$$

$\mathrm{C}_{\mathrm{h}}$ ：河流上游污染物浓度, $\mathrm{mg} / \mathrm{L}$;

$\mathrm{C}_{\mathrm{p}}$ : 污染物排放浓度, $\mathrm{mg} / \mathrm{L}$;

$\mathrm{Q}_{\mathrm{p}}$ : 废水排放量, $\mathrm{m}^{3} / \mathrm{s}$;

$\mathrm{Q}_{\mathrm{h}}$ : 河流流量, $\mathrm{m}^{3} / \mathrm{s}$ 。

（2）河流一维稳态混合衰减模式

当在平直河流稳态排入非持久性污染物时, 污 染物的浓度可采用 S-P 模式估算:

$$
c=c_{0} \exp \left(-K_{1} \frac{x}{86400 u}\right)
$$

式中:

$\mathrm{C}_{0:}$ : 计算初始断面污染物浓度, $\mathrm{mg} / \mathrm{L}$;

$\mathrm{u}$ ：河流断面平均流速， $\mathrm{m} / \mathrm{s}$;

$\mathrm{K}_{1}$ : 衰减系数;

$\mathrm{X}$ : 衰减距离。

\section{4. 城市生活垃圾安全填埋场环境污染风险管理 措施}

对垃圾安全填埋场的风险管理要贯彻全过程管 理的原则, 即从垃圾场的选址直到垃圾场的封场, 均要有风险意识。在认真贯彻落实《城市生活垃圾 卫生填埋技术规范》的前提下, 通过有效的管理, 提高填埋场对自然风险的抗御与应对能力, 减少以 至于消除设备风险及人为风险, 从而为填埋场所在 区域提供一个安全的环境。

\section{1 选址阶段的风险管理}

填埋场所选地点首先要保证地质基础稳定, 要 避开褶皱、断裂发育地点、洪泛区以及滑坡、泥石
流易发地点, 而且附近要无大的地表水体与水源 地。同时要保证与居民点之间有足够的卫生防护距 离。

\section{2 设计阶段的风险管理}

垃圾场的设计要有备用电源、设备、机械部 件, 对垃圾渗滤液收集池容量的设计要充分考虑到 处理设施故障、洪水等风险因素, 从而提高垃圾场 的抗风险能力。

垃圾填埋场的设计要具有抗震性, 充分考虑到 一旦遭到地震的损坏后的补救措施。

要填埋场内以及周围地区要布设地下水监测 井, 定期监测地下水的成分, 一旦发生防渗层破 损，做到早发现早处理。

\section{3 建设施工阶段的风险管理}

垃圾场建设材料的选择上要严把质量关, 建设 施工要严格执行工程设计规范, 尤其是建设垃圾填 埋场防渗层、导气装置、污水收集与处理设施时, 要加强建设施工的监理, 以降低甚至杜绝这些环节 出现故障而出现的风险。

\section{4 运营阶段的风险管理}

垃圾填埋场在日常的运营过程中, 要贯彻风险 意识, 要按照操作规程进行日常作业, 对入场垃圾 要及时进行平整、压实, 当垃圾达到 $2 \mathrm{~m}$ 左右的厚 度时, 要及时覆土以减少雨水的进入量, 并且要根 据所在区域的自然环境状况控制垃圾堆体的填埋厚 度。在大雨、暴雨等恶劣天气条件下, 填埋场要临 时关闭。

对污水处理设施要定期进行检测, 对污水浓 度、填埋气体的浓度要定期监测, 发现异常要寻找 问题根源及时进行处理。

\section{5 封场阶段的风险管理}

封场后要及时在垃圾堆体表面覆盖防渗层, 并 覆土进行植被恢复。应继续处理填埋场产生的渗滤 液和填埋气, 并定期进行监测。

\section{6 风险意识的培养与应急能力的训练}

针对垃圾场职工和公众广泛开展风险宣传和教 育, 组织安全培训与演习, 提高员工和公众的风险意 识和应急能力。

制定包括监测、报警及污水事故排放等情景组 合下的应急预案并定期演习, 减少突发环境事件带来 的灾难性后果。 


\section{参考文献}

[1] 朱东升,黄佺,胡海兰,环境风险评价的进展,职业与健康. 25(14) (2009) 1537-1539.

[2] 韩东升,肖国芽,谢雯, 城市垃圾填埋场环境风险评价浅析, 污染防治技术. 36(10) (2007) 20-23.

[3] 段小丽,王宗爽,于云江等,垃圾填埋场地下水污染对居民 健康的风险评价,环境监测管理与技术. 20(3) (2008)20-24.

[4] 王炜,张小梅,刘茂,垃圾填埋场火灾爆炸风险分析, 环境卫 生工程. 13(5) (2005) 41-44,47.

[5] 龙腾锐, 易洁, 林于廉等, 垃圾渗滤液处理难点及其对策研 究,士木建筑与环境工程. 31(1) (2009)114-119.

[6] 曹希寿,区域环境风险评价与管理初探, 中国环境科学. 14(6) (1994)465-470.

[7] 宋国君,马中,陈婧等.论环境风险及其管理制度建设, 环 境污染与防治. 28(2)（2006）100-103.

[8] 徐惠民,区域环境风险综合评价理论与方法探讨,东北师 范大学硕士学位论文.1995. 